\title{
Caso Clínico Radiológico
}

\author{
JULIO MAGGIOLO M. ${ }^{1}$, LILIAN RUBILAR O. ${ }^{1}$, RICARDO KOGAN A. ${ }^{1}$, \\ GUIDO GIRARDI B. ${ }^{2}$, CARLOS VILDÓSOLA S. ${ }^{3}$ \\ 1. Médico, Unidad Broncopulmonar. Hospital Exequiel González Cortés. \\ 2. Médico, Profesor Asociado de Pediatría. Campus Sur. Universidad de Chile. \\ 3. Médico, Servicio de Radiología. Centro Médico Fleming.
}

\section{Caso clínico}

Niña de 1 mes y 15 días, hija de padres sanos, parto de término eutócico y sin antecedentes mórbidos neonatales. Inició síntomas respiratorios, en ausencia de fiebre, caracterizados por tos paroxística con cianosis peribucal y obstrucción bronquial leve. Fue tratada con salbutamol en inhalador de dosis medida (MDI) y eritromicina por 14 días pese a lo cual empeoró progresivamente, siendo hospitalizada a los 2 meses de edad en insuficiencia respiratoria aguda. A su ingreso al Servicio de Urgencia de nuestro hospital destacaba ausencia de compromiso séptico, afebril, dificultad respiratoria moderada con FR de $56 \mathrm{x}^{\prime}$, retracción de partes blandas y saturación de oxígeno de $88 \%$ que mejoró a valores de 95\% con 2 l/min de oxígenoterapia. La figura 1 muestra la radiografía de tórax en proyección AP a su ingreso.

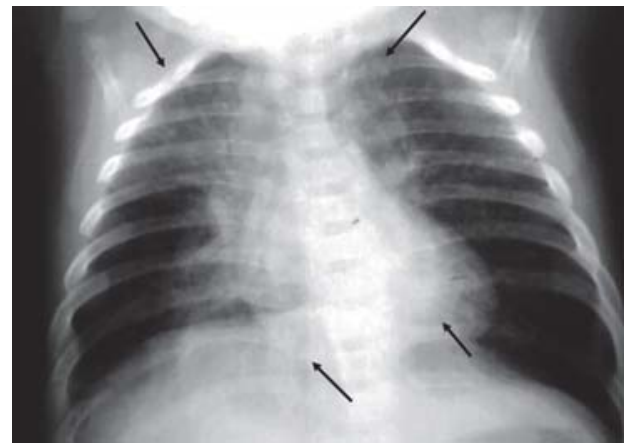

Figura 1.
La inmunofluorescencia indirecta (IFI) confirmó el diagnóstico de infección respiratoria aguda baja (IRAB) por virus respiratorio sincicial (VRS) y se planificó tratamiento con oxigenoterapia, salbutamol MDI y corticoides sistémicos.

Evolucionó afebril, con tos en accesos y cianosis peribucal, recibiendo tratamiento empírico por 14 días con eritromicina oral pese a inmunofluorescencia directa (IFD) para Bordetella pertussis negativa. El laboratorio de apoyo demostraba hemograma, PCR y electrolitos en sudor normales, 3 baciloscopías de contenido gástrico negativas, estudio inmunológico normal y ELISA para VIH negativa. Por persistir con requerimientos de oxigenoterapia y haber progresión de los hallazgos radiológicos (figura 2) el día 30 de evolución se decidió realizar fibrobroncoscopía para practicar lavado broncoalveolar (LBA).

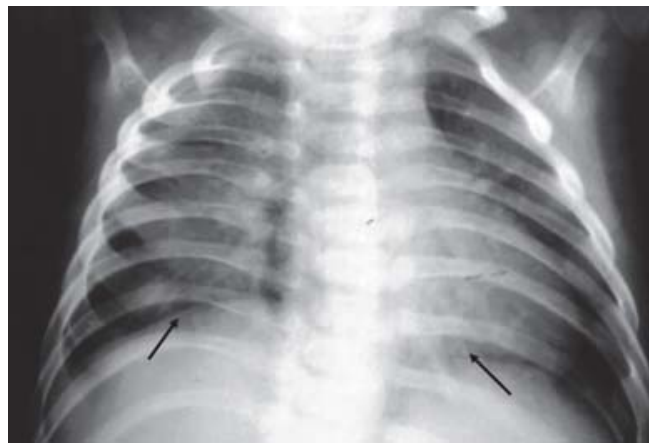

Figura 2.

\section{¿Cuál es su diagnóstico?}

Trabajo recibido el 25 de octubre de 2007, devuelto para corregir el 22 de noviembre, segunda versión el 30 de noviembre de 2007, aceptado para publicación el 15 de diciembre de 2007.

Correspondencia a:

Julio Maggiolo M

E-mail: julio_vrs@latinmail.com 


\section{Hallazgos radiológicos}

La figura 1 muestra extensos infiltrados intersticiales retículo-nodulares y lineales, que comprometen ambos campos pulmonares con insuflación pulmonar moderada.

En la figura 2 se observa progresión de los infiltrados intersticiales, en forma difusa y bilateral, con compromiso hasta la periferia pulmonar, dibujando discreto broncograma aéreo. En forma concomitante, el cultivo rápido (shell vial) en LBA y orina fueron (+) para citomegalovirus (CMV). El resto de exámenes de diagnóstico microbiológico del LBA no confirmaron otras etiologías posibles, microinmunofluorescencia (MIF) para la detección de IgM anti Chlamydia trachomatis, tinción GomotGrocott y reacción en cadena de la polimerasa (PCR) para Pneumocystis jiroveci, cultivo corriente y de hongos negativos.

La figura 3 corresponde al control radiológico después de 45 días de evolución, momento en que presenta mejoría clínica y es posible suspender el aporte de oxígeno. Se observa escasos infiltrados intersticiales de carácter residual.

Debido a esta favorable evolución no es tratada con antivirales, siendo dada de alta en buenas condiciones.

Actualmente, la paciente tiene 4 años de edad y presenta síntomas episódicos infrecuentes de obstrucción bronquial.

\section{Diagnóstico}

Neumonía intersticial del primer trimestre por VRS y CMV.

\section{Discusión}

La etiología más frecuente de IRAB en lactantes son los virus y de ellos el VRS con un claro comportamiento epidémico durante el invierno. Clínicamente y sobre todo en el menor de 6 meses se presenta con signología bronquial obstructiva, neumonía, síndrome coqueluchoídeo o apnea. Existe una proporción varia-

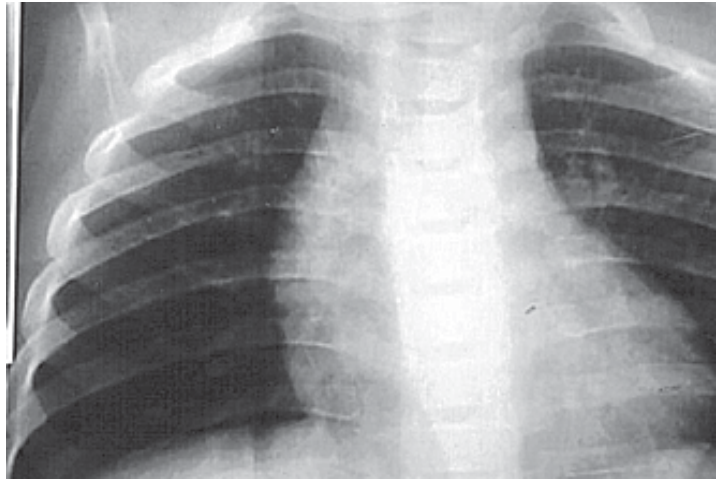

Figura 3.

ble de coinfección con bacterias y otros virus que no se vincula necesariamente con mayor gravedad.

La presentación clínica de síndrome coqueluchoídeo y neumonía intersticial en un lactante sano menor de 12 semanas, obliga a considerar el diagnóstico diferencial de otros agentes etiológicos como son Bordetella pertussis y Chlamydia trachomatis. En la actualidad se cuenta con diagnósticos microbiológicos rápidos como son la IFD y la PCR en el caso de la Bordetella y la MIF en sangre para la segunda. Nuestra paciente fue tratada en 2 oportunidades en forma empírica con macrólidos sin mejoría clínica, más aún con progresión radiológica, síntomas insidiosos y requerimientos prolongados de oxígeno, curso clínico poco probable para ambos agentes.

La fibrobroncoscopía como ayuda diagnóstica para obtener muestra de secreción bronquial mediante LBA, está indicada en IRAB en la que se sospecha una segunda posibilidad diagnóstica en el curso evolutivo inhabitual como el que presentó esta paciente. El uso de nuevas técnicas de diagnóstico molecular como la PCR aumenta su utilidad, es así como el estudio para Pneumocistis jiroveci negativo hace muy improbable la participación etiológica de este germen oportunista.

Otro agente etiológico no estudiado en nuestra paciente y en que la PCR es la técnica diagnóstica de mayor rendimiento es el metapneumovirus, que da cuenta de un número importante de IRAB sin etiología confirmada por los métodos clásicos de IFI y que también 
puede ser coinfección de IRAB con VRS. Está en plena discusión si esta coinfección se relaciona con una evolución más tórpida, no obstante esta generalmente se vincula a síndrome de dificultad respiratoria y no a neumonías intersticiales.

En definitiva, en la paciente reportada, el diagnóstico de neumonía del primer trimestre por CMV se sostiene fundamentalmente en la evolución clínica y radiológica compatible en un lactante menor con otras etiologías razonablemente descartadas en el que se precisó su presencia por la técnica de aislamiento acelerado en una muestra de LBA y orina. No obstante, tanto en el paciente inmunocompetente como inmunosuprimido la verificación de excreción de CMV en orina y LBA no puede asignar fehacientemente causalidad.

Salvo en pacientes de alto riesgo con inmunocompromiso, situación también razonablemente descartada por los exámenes de laboratorio realizados o inmunocompetentes que presenten un cuadro clínico grave con riesgo vital, la neumonía por CMV no tiene indicación de tratamiento con antivirales (ganciclovir), estos fármacos pueden producir efectos colaterales especialmente a nivel hematológico.

\section{Referencias}

1.- Feigin RD, Cherry JD: Cytomegalovirus. In: Textbook of Pediatric Infectious Diseases. 4a Edition. WB Saunders Company, 1998.

2.- Enright A, Prober $\mathrm{CH}$ : Herpesviridae infections in newborns: varicella zoster virus, herpes simplex virus and cytomegalovirus. Pediatr Clin N Am. 2004; 51: 889-908.

3.- Stagno S, Brasfield DM, Brown MB, et al: Infant pneumonitis associated with cytomegalovirus, chlamydia, pneumocystis, and ureaplasma: a prospective study. Pediatrics 1981; 68: 322.

4.- Cohen JI, Corey GR: Citomegalovirus infection in the normal host. Medicine 1985; 64: 100.

5.- Mustafa Mahmoud F: Cytomegalovirus infections and disease in the immunocompromised host. Pediatr Infect Dis J 1994; 13: 249-59.

6.- Escobar AM, Martínez F, Ceruti E, et al: Etiología de las infecciones agudas del tracto respiratorio bajo (IRAB) en lactantes hospitalizados: estudios virológicos. Rev Chil Pediatr 1988; 59 (6): 349-53.

7.- Hammerschlag M: Chlamydia and Chlamydiales: beyond Chlamydia trachomatis. Pediatr Infect Dis 2007; 26: 639-40.

8.- Perret C, Vial P, Viviani T, Gonzalez A, Montiel F: Etiología del síndrome coqueluchoídeo y rendimiento de las técnicas para el diagnóstico de Bordetella pertussis en pacientes hospitalizados. Rev Chil Infect 1999; 16 (1): 17-26.

9.- Semple MG, Cowell A, Dove W, et al: Dual infection of infant by human metapneumovirus and human respiratory syncytial virus is strongly associated with severa brochiolitis. J Infect Dis 2005; 191: 382-6.

10.- Crowe JE: Human Metapneumovirus as a Major Cause of Human Respiratory Tract Disease. The Pediatr Infect Dis J 2004; 23: 215-26.

11.- Stagno S, Brito W, Pass R: Cytomegalovirus. En: Schmidt N, Emmons R: Diagnostic procedures for viral, rickettsial and chlamydial infections. 6a ed. Washington: American Public Health Ass 1989; 321-78.

12.- Gleaves CA, Smith TF, Shuster EA, Pearson GR: Rapid detection of cytomegalovirus in MRC-5 cells inoculated with urine specimens by using low-speed centrifugation and monoclonal antibody to an early antigen. J Clin Microbiol 1984; 19: 917.

13.- Jespersen DJ, Drew WL, Gleaves CA, et al: Multisite evaluation of a monoclonal antibody reagent for rapid diagnosis of cytomegalovirus in the shell vial assay in BAL. J Clin Microbiol 1989; 27: 1502.

14.- Ljungman $P$, Engelhard $D$, Link $H$, Biron $P$ : Treatment of interstitial pneumonitis due to cytomegalovirus with ganciclovir and intravenous immune globulin: experience of European Bone Marrow Transplant Group. Clin Infect Dis 1992; 14: 831.

15.- Arancibia ME, Cordero J: Tratamiento con ganciclovir en neumonía intersticial por citomegalovirus. Rev Chil Pediatr 1993; 64 (4): 241-4. 